BRAZILIAN JOURNAL

OF

RADIATION SCIENCES

08-03 (2020) 01-12

\title{
Computer simulator for the research reactor IPEN/MB-01
}

\author{
Casorla $^{a}$ M., Bitelli ${ }^{\mathrm{a}}$ U. D., Andrade ${ }^{\mathrm{a}}$ D. A, Rocha ${ }^{\mathrm{a}}$ M. S. \\ ${ }^{a}$ Nuclear and Energy Research Institute - IPEN/CNEN, Nuclear Engineering Center-CEENG, 05508-000, \\ Prof. Lineu Prestes Av. 2242, São Paulo, SP, Brazil \\ msrocha@ipen.br
}

\begin{abstract}
A computer simulator for the Nuclear Research Reactor IPEN / MB-01 was developed to be a tool for teaching, training, and recycling professionals. The simulator was developed on a SCADA platform (Supervision and Data Acquisition System) with support calculation software, where mathematical models, and graphical interface configurations form a friendly platform, which allows the trainee to be identified with the physical systems of the research reactor. Simplified modeling of the main physical phenomena related to the operation of the reactor, and the reactivity control systems, reactor cooling and reactor protection was used. The Simulator allows an HMI (Human-Machine Interaction) by manipulating system variables and monitoring trends in quantities during the operation of the reactor, showing an interactive tool for teaching, training and recycling for professionals in the Nuclear Reactor IPEN / MB -01, allowing simulations of the start, power and stop operations.
\end{abstract}

Keywords: nuclear research reactor, computational simulator, operator training. 


\section{INTRODUCTION}

The use of computer simulators has become more common in different areas of human activity. They are more necessary the greater the complexity of systems and their interactions with operators. The level of security required, depending on the possible consequences of the wrong operation, is a key factor for using training and retraining policies of the operators of those systems. Clear examples are the necessary policies for training and retraining aircraft pilots, ships, automobiles, complex industrial plants, and, mainly, nuclear reactors.

The safety requirements of a nuclear reactor, from its planning to its decommissioning through its operation, are reasons for much study and debate among the experts responsible for establishing the standards that govern this industry. Several institutions are performing this function in the world, but the International Atomic Energy Agency (IAEA) [1-3] is the main international institution that develops and recommends such standards. In Brazil, the Brazilian Nuclear Energy Commission (Comissão Nacional de Energia Nuclear - CNEN) is the governmental institution that regulates nuclear activities, including nuclear reactor operation.

Nuclear reactors are highly complex systems, containing several subsystems operating under the supervision of a hierarchical structure composed of directors, supervisors, and operators trained and trained over a long period. Be nuclear power reactors, be research nuclear reactors, the requirements of operation safety are also severe. Thus, the training of these operators is a key factor in ensuring the safety of these facilities.

For nuclear research reactors, the IAEA has developed a safety guide on training and qualification aiming for the good training of operators [4]. It includes the nature of the operational organization, and guidance on its establishment; the recruitment process for reactor personnel, including the required qualifications; the initial training and recycling programs of personnel and the authorization process for individuals whose functions were an immediate relationship with safety. According to the guide, the training methods cover, among other recommendations, training in simulators.

The IAEA [4] reinforces the need to use computational tools that satisfactorily simulate the behavior of the systems and subsystems of a nuclear reactor as a way of training operators under 
various operating conditions. The focus of that document is to present up-to-date information on classification, selection, and use of simulators for education and training.

Besides, nuclear power reactor operators around the world make use of high-capacity computer simulators to reproduce from those facilities. The same effort has been made for research reactor operators around the world, coordinated by the IAEA [3].

In this context, a research project was carried out to develop a computational simulator that reproduces the operational behavior of the IPEN/MB-01nuclear research reactor, seen at Fig. 1.

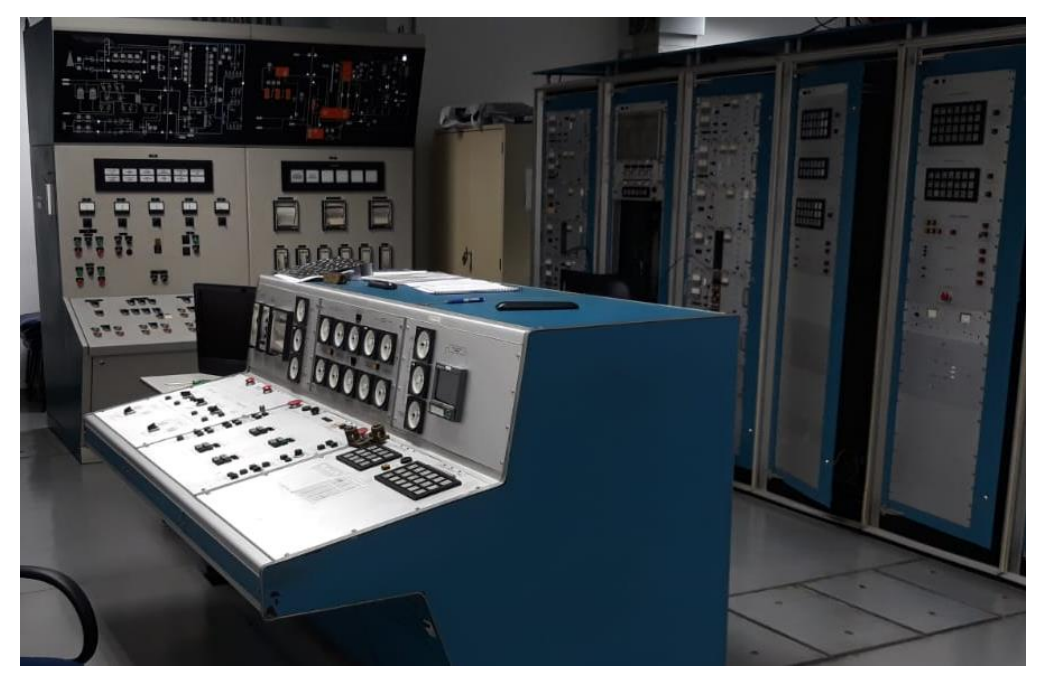

Figure 1: Control room of the Nuclear Research Reactor IPEN/MB-01.

The IPEN/MB-01 research reactor is a zero-power reactor, whose function is to allow researchers to conduct experimental neutronic studies for comparison with theoretical calculations, performance and characteristics of core configuration, and operator training. It is located at the Nuclear and Energy Research Institute (IPEN-CNEN/SP), in the city of São Paulo, Brazil [12].

The IPEN/MB-01 reactor core, for which the simulator was developed, has a rectangular shape with active dimensions of $390 \times 420 \times 546 \mathrm{~mm}$, with an arrangement of $28 \times 26$ positions of fuel rods and 48 guide tubes, intended for the insertion of control and safety rods, responsible for the control of the reaction chain, and reactor SCRAM. For this core configuration, there are a total of 680 fuel rods with an excess reactivity of approximately $2400 \mathrm{pcm}$. The fuel rods are made up of 
stainless steel tubes, containing inside 52 fuel tablets of uranium dioxide $\left(\mathrm{UO}_{2}\right)$ enriched at $4.3 \%$. The reactor core is installed inside a tank that can have the water level controlled. Other characteristics can be obtained in [12].

It is noteworthy that, currently, the IPEN/MB-01 reactor core was changed and it is composed of fuel elements of the parallel plate type.

\section{MATERIALS AND METHODS}

\subsection{Nuclear Reactors Computer Simulators}

Nuclear reactor computer simulators are numerical codes (which may contain multiple codes) to provide an insight and understanding of the plants, as well as a clear understanding of the operational characteristics of the reactors. Simulators are educational tools for training. They seek to provide general response characteristics of selected types of reactors systems.

Simulators can be classified into basic training and training simulators and professional simulators. According to [6], the basic training and training simulators present general concepts, demonstrating and exhibiting the fundamental physical processes of the reactors. These simulators are sometimes called basic principle simulators and are available for all major types of facility projects. They do not always faithfully reflect a particular plant. Its goal is to help users to understand fundamental physical processes, basic operation, and layout of NPP's, general operating systems, and procedures. They are used in primary and higher education programs, and can be as follows:

- Simulators of partial tasks: they deal with a specific part of the plant operations (systems or components) or specific phenomena;

- Complete simulators: describe an overview of plant behavior, focusing on the main systems, with or without auxiliary systems.

Several part computer simulators have been developed to simulate specific part-task or full reactors systems or to training specifi skills on operators [5-8].

Professional simulators represent complete plant components and systems and their functions, comprehensive operation processes, or internal effects at several levels and system parameters of a 
specific plant, during normal, transient or accident conditions. For such characteristic, they are intended for the specific representation of a particular type of reactor, and they are developed by manufacturers for training their operators [4].

The main technical characteristics of a training simulator are:

- Good human-machine interface;

- Well-defined modeling scopes for each objective and simulator components faithful to the real ones;

- Clear and timely information output (graphics, data, and warnings);

- Simulator developer must provide operation information with a manual;

- Other considerations such as interlocking systems are important.

This work aims to develop a computational simulator of basic training, using data and characteristics obtained during the actual operations of the IPEN/MB-01 research reactor. The simulator was developed according to the control design techniques [9-10]

\subsection{The IPEN/MB-01 Research Reactor Computational Simulator}

The IPEN/MB-01 research reactor computer simulator was developed based on two distinct and complementary platforms. The first is a SCADA (Data Acquisition and Supervision System) platform, which serves as a human graphical interface (HGI) and control between the operator and the reactor systems, and a data processing platform (DPP).

On the HGI platform it is possible:

- Positioning of the control bars, and safety of the reactor;

- Control the moderator temperature;

- Control the moderator level;

- Change the core configuration;

- To do intervention of the interlock in the reactor control;

- $\quad$ Run SCRAM when it is needed.

Thus, the behavior of the following physical parameters and reactor operation is verified:

- Operation, intervention and shutdown of the reactor; 
- Operation of radiation detectors;

- Determination of the $1 / \mathrm{M}$ curve versus position of the control bars;

- Obtaining calibration curves for each reactor core configuration;

- Influence of the level and temperature of the moderator on the reactivity of the reactor core;

- The measure of the coefficient of reactivity to empty of the reactor;

- Future ones that may be introduced by experts.

The simulator focuses on synoptic panels such as HGI being, therefore, limited to the performance of data processing that efectively simulates the actual reactor operations. Thus, for mathematical modeling, the resources of software that performs the calculation quickly and accurately enough to give the operator the feeling of real-time operation was used. In this simulator was used the software Matlab (Simulink Module) (DPP), allowing direct links with Indusoft, a Microsoft SCADA system (HGI). The communication between this two software established via an Ole for Process Control (OPC) port, enabling the integration between the two proposed systems. For this, it was necessary to insert two blocks in the DPP environment: OPC (OPC Configuration) and OPC (Client Manager) and make the proper configuration of the two software to ensure the sending and receiving of the operation information in real-time.

The simulator can be installed on a server, running the software. The trainees or students will be held in a laboratory where students will have access to the internet through a browser on each PC. The operation of the simulator is done remotely with restricted access for each objective currently proposed.

The simulator is based on data obtained from hundreds of real operations over the years, whose data has been stored in a database [11]. This database contains all the information provided by the Data Acquisition System (SAD) of the research reactor IPEN/MB-01, which contains data from nuclear channels, detectors, positioning of control bars, level, temperature, and water quality in the core water tank, among others. These data were organized into tables.

It was necessary to transform each variable stored in the table into valid data for the DPP software that does the data processing. In this way, the variables created were imported to be used as data to be used by the System Identification Toolbox. After performing the entire data acquisition and preparation procedure, each data set was approximated to a transfer function by specific models 
for each existing function. The tool has several models that can be used, from the simplest as a transfer function to the most complex ones as nonlinear models. When choosing a particular model to be estimated, the developer must pre-determine iteratively, or with some prior knowledge of the process, coefficients, and other parameters of the model. For example, in a transfer function model, it must choose the number of poles and zeros, and in polynomial models, the user has to determine the order of arbitrary polynomials.

In Figure 2 it is possible to check two examples of supervisory HMI screens built for the simulator.

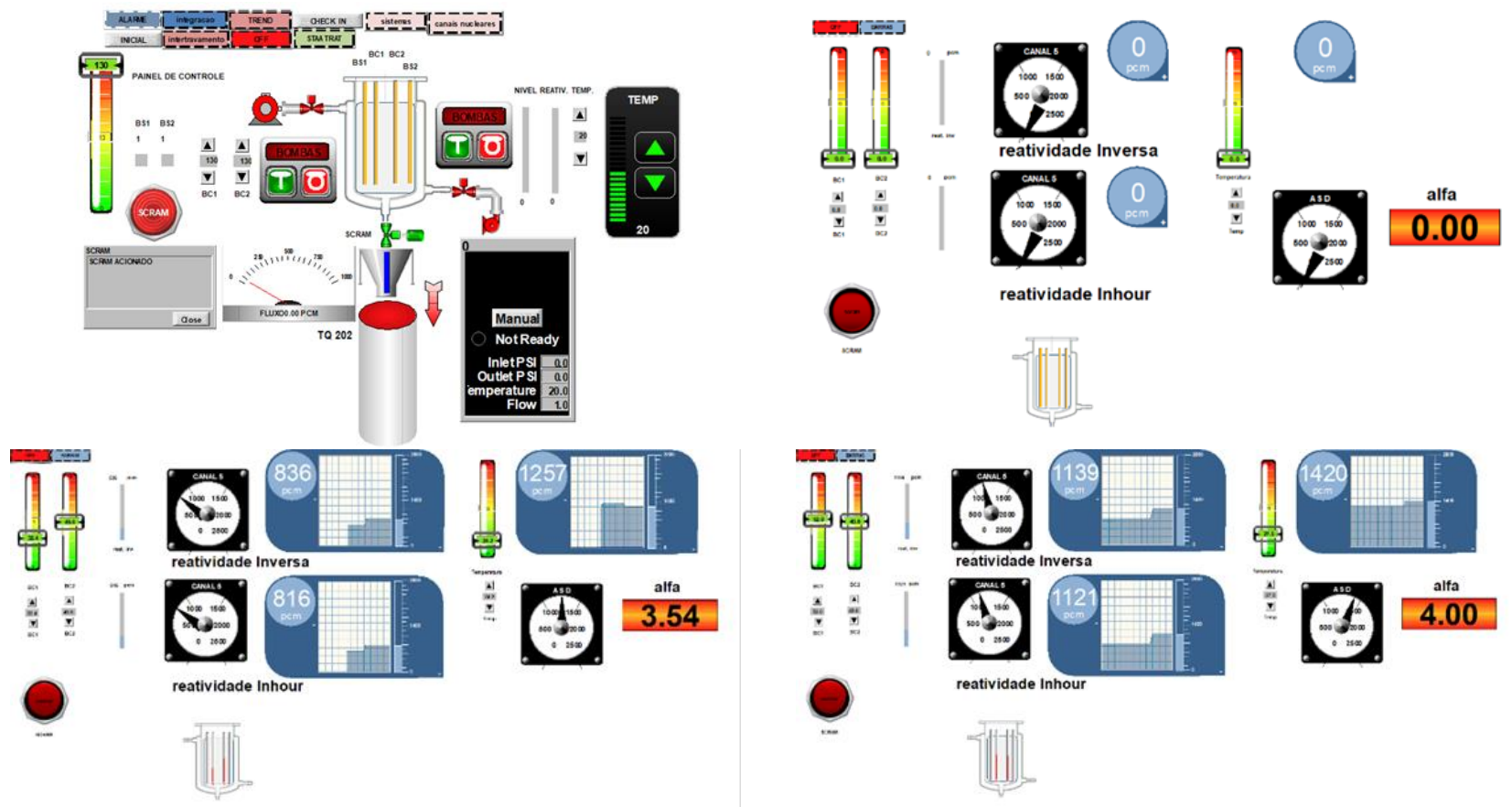

Figure 2: Supervisory HMI screens built for the simulator.

By activating both software (HGI and DPP) one gets the presented outputs in the HGI as a function of the inputs, such as results of the reverse and Inhour reactivity and the alpha coefficient of the chosen configuration. There is also the possibility of obtaining dynamic information, such as responses from the PID control (Proportional-Integral-Derivative, as observed in Fig. 3. 


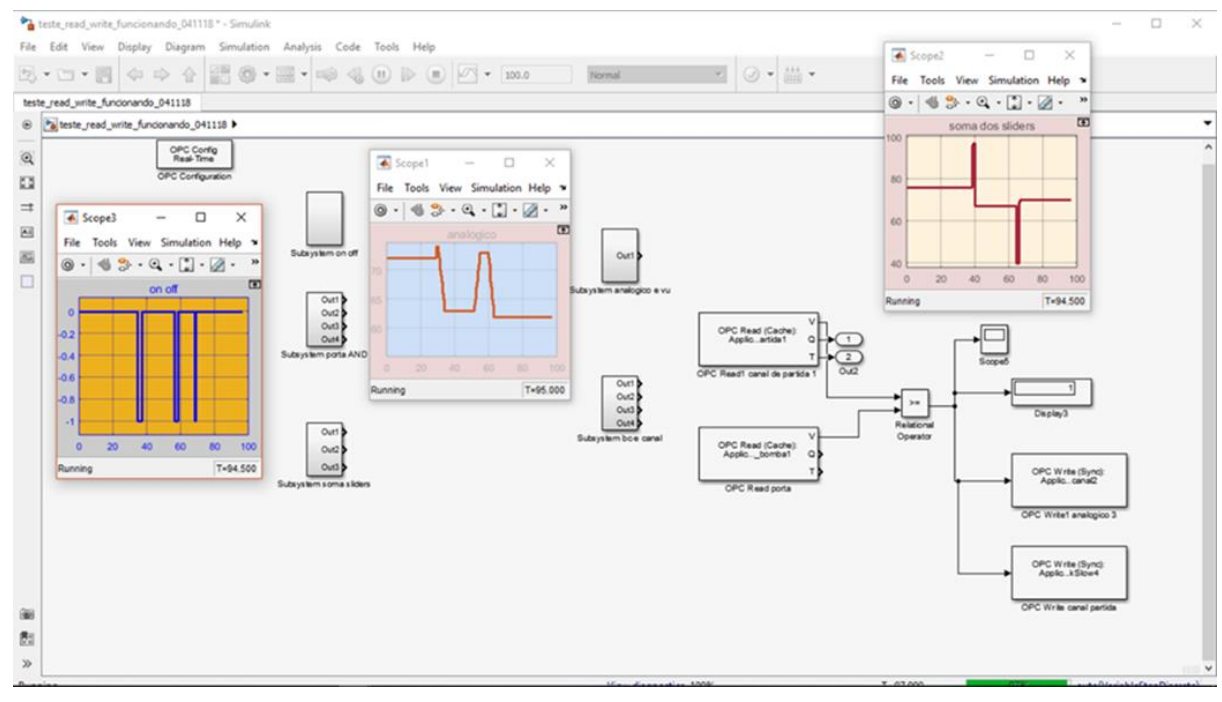

Figure 3: PID control response example.

It must be pointed out that this first version of the computer simulator of the IPEN/MB-01 can reproduce just one of the various kernel configurations. The other configurations will be implemented.

\section{RESULTS}

Results of the experiments carried out in the reactor such as inverse and Inhour reactivity and the alpha coefficient as a function of the moderator's temperature are some of the parameters presented by the simulator, as can be seen in Fig. 4 . 


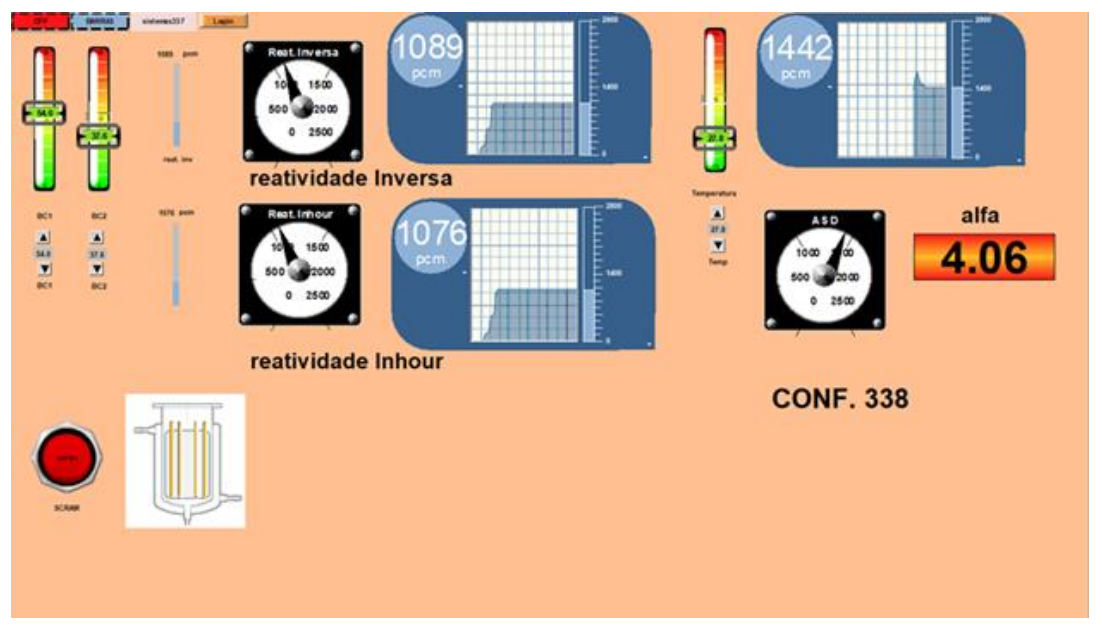

Figure 4: Inhour, inverse, and reactivity coefficient responses for configuration 338.

Results can also be obtained from the nuclear channels obtained in the reactor experiments, as shown in Fig. 5.

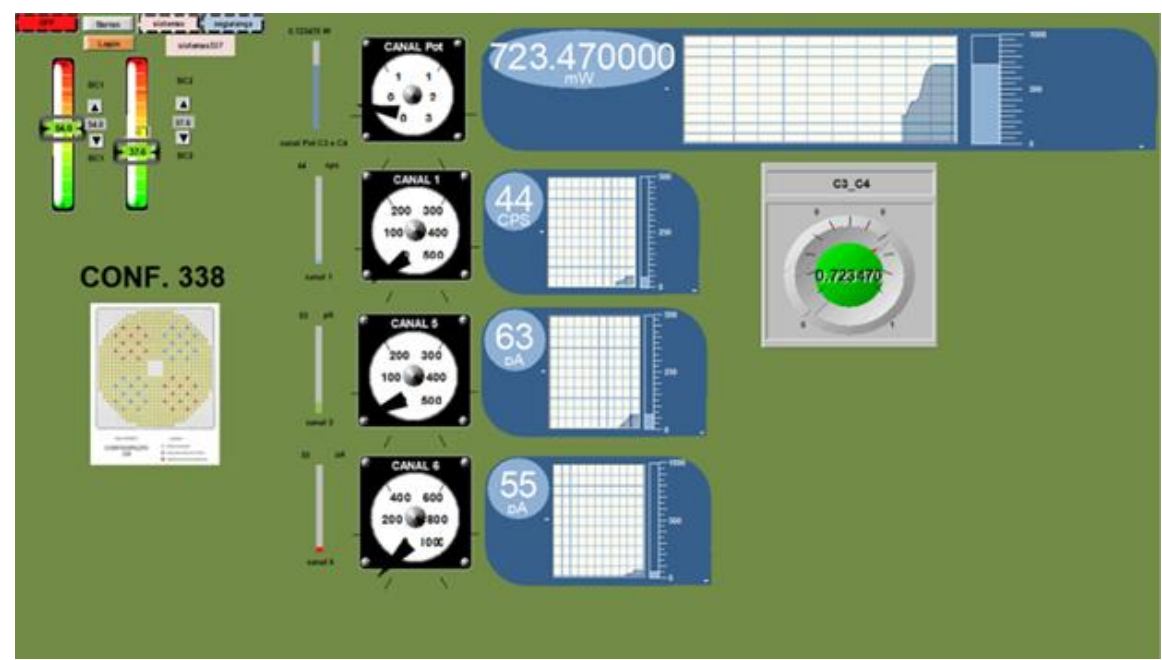

Figure 5: Results of channels 1, 5, and 6 for configuration 338. 
Another system represented by the simulator is the reactor water treatment system (STAA). Knowledge of this subsystem is fundamental for operator training. The screen shown in Fig. 6 shows the STAA.

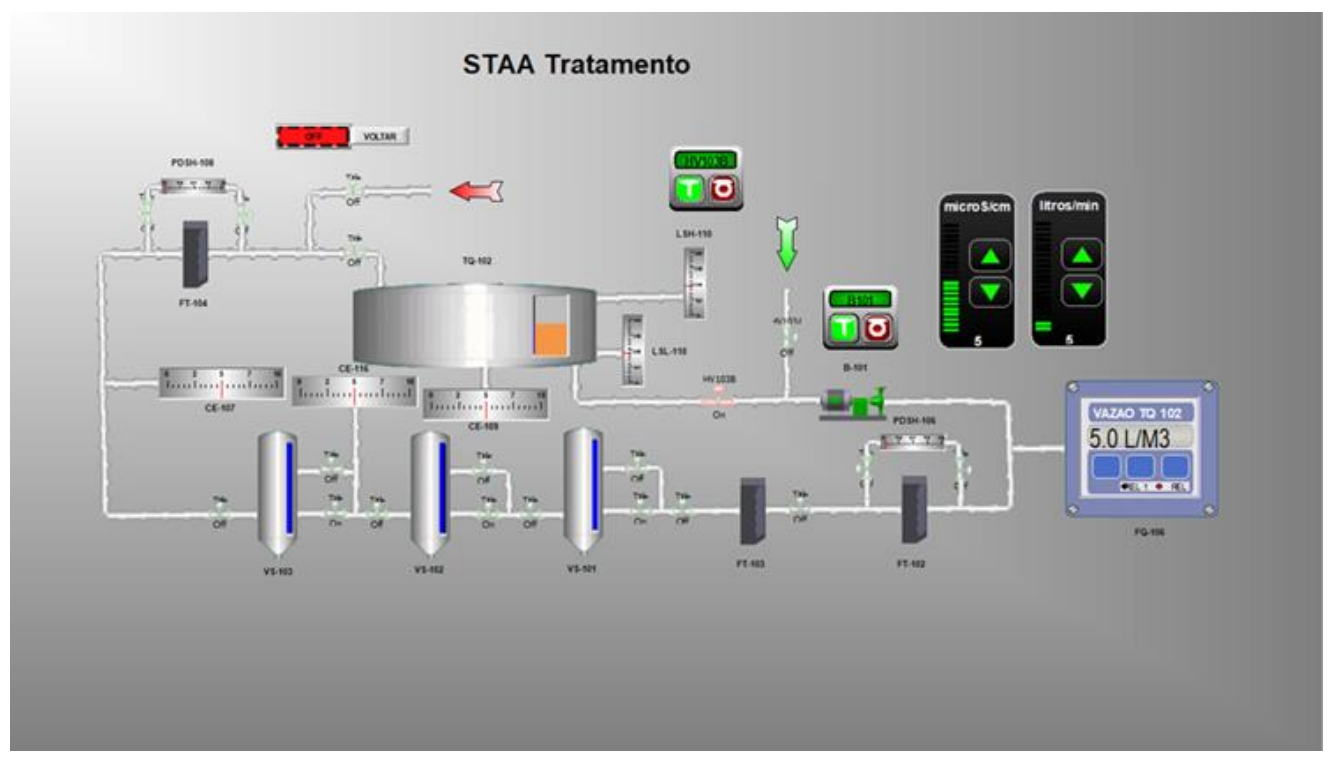

Figure 6: STAA Treatment System Screen.

\section{CONCLUSIONS}

A computational simulator was developed for the IPEN/MB-01 nuclear research reactor, developed for mono or multi-user systems. It performs a simulation of the main operational variables of the reactor, also allows easy navigation between HMI screens providing globalized supervision of neutronic, thermal, and hydraulic processes if implemented. It was possible to show the feasibility of integrating a supervisory system and software to perform mathematical calculations with the data obtained from real experiments. The system identification and Matlab resource for SCADA was used through OPC. The benefits and advantages of using the simulator based on personal computers during the training programs of operators and undergraduate and graduate students were shown. Improvements to human-machine interfaces can be implemented to make the simulator more effective in training. 


\section{ACKNOWLEDGEMENTS}

The authors thank the management of the IPEN/MB-01 reactor for supporting and providing the experimental data. They also thank IPEN/CNEN for allowing the development of the work.

\section{REFERENCES}

[1] INTERNATIONAL ATOMIC ENERGY AGENCY. Experience in the use of systematic approach to training (SAT) for nuclear power plant personnel, Vienna, 1999. Technical Document Series, 1057p.

[2] INTERNATIONAL ATOMIC ENERGY AGENCY. Safety of nuclear power plants: operation, Vienna, 2000. Safety Standards Series, NS-R-2.

[3] INTERNATIONAL ATOMIC ENERGY AGENCY. Recruitment, qualification and training of personnel for nuclear power plants, Vienna, 2002. (Safety Standards Series, NS-G-2.8).

[4] INTERNATIONAL ATOMIC ENERGY AGENCY. The operating organization and recruitment, training and qualification of personnel for research reactor, Vienna, 2002. Safety Standards Series, NS-G-2.8.

[5] CARVALHO, R. P.; MAIORINO, J. R.. A Research Reactor Simulator for Operators Training and Teaching, PHYSOR-2006, ANS Topical Meeting on Reactor Physics, Vanvouver, 2006. p. 1-7.

[6] LAGE, A. M. F.; FELIPPE, A. A. M.; MESQUITA, A. Z.. Design of a digital system for operational parameters simulation of IPR-R1 Triga nuclear research reactor. Brazilian Journal of Radiation Sciences, v. 07-02B, 2019, p. 01-13. DOI: https://doi.org/10.15392/bjrs.v7i2B.

[7] ARAFA, A.; SALEH, H. I.; ASHOUB, N.. Design and implementation progress of multipurpose simulator for nuclear research reactor using LabVIEW. Kerntechnik, v. 80, 2015, p. 111. DOI: $10.3139 / 124.110535$.

[8] ARAFA, A.; SALEH, H. I.; ASHOUB, N.. Development of an educational nuclear research reactor simulator. Kerntechnik, $\quad$ v. $\quad 79, \quad 2014, \quad$ p. $\quad 518-527$. https://doi.org/10.3139/124.110446. 
[9] BANKS, J.. Handbook of Simulation: Principles, Methodology, Advances, Applications, and Practice. N.Y.: JOHN WILEY \& SONS, 1998. 849p.

[10] OGATA, K.. Engenharia de Controle Moderno. São Paulo: PEARSON - Prentice Hall, 2010. 824p.

[11] BITELLI, U. D., Experimentos na Fase de Comissionamento - Comparação com a Metodologia de Cálculo. Relatório Interno RELT 003.R00, São Paulo. Outubro, 1998.

[12] Available at <https://www.ipen.br/portal_por/portal/interna.php?secao_id=723>. Last accessed: 10 July 2020. 